\title{
The impact of General Dental Council registration and continuing professional development on UK dental care professionals: (2) dental technicians
}

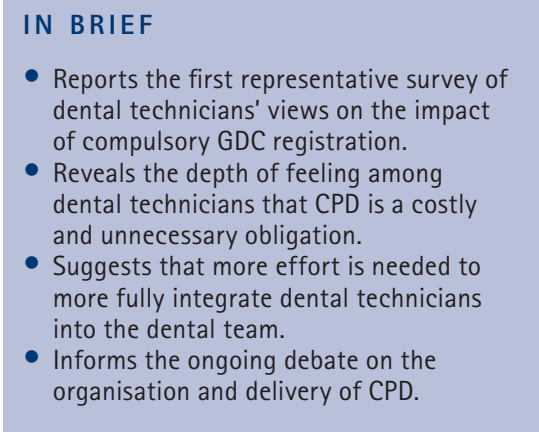

- Reports the first representative survey of dental technicians' views on the impact of compulsory GDC registration.

Reveals the depth of feeling among dental technicians that CPD is a costly

Suggests that more effort is needed to into the dental team.

organisation and delivery of CPD.

\author{
M. K. Ross, ${ }^{1}$ S. Turner ${ }^{2}$ and R. J. Ibbetson ${ }^{3}$
}

Objective To investigate the impact of General Dental Council (GDC) registration and mandatory CPD on dental technicians' views, job satisfaction and intention to leave the profession. Design Postal/online survey, conducted in parallel with a survey of dental nurses. Setting UK private and NHS practices, community services, dental hospitals. Subjects and methods Representative sample of GDC registrants. Main outcome measures: job satisfaction; intention to leave profession (dependent variable in regression analysis). Results 605 were sampled: 40 were ineligible (left the register in July 2011, re-qualified in another dental care profession, shared a practice address with another selected DT); 193 responded (response rate 34\%). 22\% were female (mean age 38.2 years) and 78\% male (mean age 49.4 years). The general principle of registration was endorsed by 52\%, and compulsory registration by $54 \%$, but the fee level by only $13 \%$. Most technicians felt that registration had had either no effect or a negative effect on their view of their career (80\%), role (78\%) or status within the dental team (85\%), and 66\% did not agree that training helped them to do their job better. Fifty-one percent were not satisfied with their job and 20\% intended to leave the profession. Intention to leave was predicted by greater dissatisfaction with remuneration. Conclusions Criticisms regarding the cost and relevance of registration and the cost, relevance and accessibility of CPD, coupled with potentially high level of attrition from the profession, suggest a review of the fee and salary structure and greater support for CPD is warranted.

\section{INTRODUCTION}

The General Dental Council (GDC) register of UK dental practitioners includes 6,636 dental technicians (DTs). ${ }^{1}$ According to the GDC their role is to 'make dentures, crowns and bridges to a prescription from a dentist or clinical dental technician. They also repair dentures direct from members of the public.'2 Unlike other groups of GDC registrants, the number of registered DTs is declining, from 7,460 at the end of 2008 to 6,636 at the end of 2011 , representing a $11 \%$ decrease in three years. ${ }^{1,3}$ Over the same period the number of dentists increased by $8 \%$, dental hygienists by $11 \%$ and dental nurses by $4 \%$. Worryingly,

$1^{*}$-3 Edinburgh Postgraduate Dental Institute University of Edinburgh, 4th Floor, Lauriston Building, Lauriston Place, Edinburgh, EH3 9HA

*Correspondence to: Margaret Ross

Email: Margaret.K.Ross@ed.ac.uk

\section{Refereed Paper}

Accepted 19 July 2012

DOI: 10.1038/sj.bdj.2012.958

${ }^{\circledR}$ British Dental Journal 2012; 213: E13 whilst there is a decline in numbers, there is an increasing workload. For example, between 2009/10 and 2010/11 there was a $5 \%$ increase in the number of completed NHS courses of treatment in England involving new dentures or bridges. ${ }^{4}$

As with other groups of dental care professionals such as dental nurses and hygienists, registration with the GDC and completion of a given number of CPD hours has been mandatory for dental technicians since 2008. Registration involves validation of qualifications or experience and payment of an annual retention fee. Registrants must complete and record at least 150 hours CPD over a five-year cycle, with a minimum of 50 hours being verifiable. It was hoped that the introduction of mandatory GDC registration and CPD for DCPs would lead to better integration of the dental team and higher standards of clinical knowledge and activity. While there were concerns that a rigid training programme and compulsory examinations could exacerbate recruitment problems among dental nurses, ${ }^{5,6}$ little attention seems to have been given to the possible impact on dental technicians.

There is some evidence of the need for reform. A 2005 study of 250 DTs in Scotland found that only $47 \%$ had attended an educational event within the preceding year, and of those who had not done so, an average period of two years had elapsed since any CPD involvement. Sixty-four percent felt they were out of date with professional education. Cost was a problem for many: only 34\% stated that any financial assistance had been available for educational purposes, and access to education was problematic for $68 \%$. $^{7}$

A 2011 GDC-commissioned literature review noted that while there were several papers on the impact of CPD for dentists, there were far fewer studies relating to other dental professions. ${ }^{8}$ This deficiency was to some extent addressed in late 2011 when the GDC commissioned a large scale 
survey of a representative sample of all GDC registrants regarding perspectives on mandatory CPD. ${ }^{1}$ Time, cost and distance were cited as the main barriers for CPD completion, with $71 \%$ of responding DTs paying for courses themselves. The survey did not address views on GDC registration, job satisfaction or career intentions.

The aim of the present study was to investigate the impact of GDC registration and mandatory CPD on a representative sample of dental technicians working in the UK in respect to their views, working practices, role within the dental team, training experience, job satisfaction and intention to leave the profession. It complements a similar study of dental nurses undertaken shortly before the present study.

\section{METHOD AND MATERIALS}

Methods and materials were identical to those employed in the survey of dental nurses. The GDC register of dental care professionals was obtained from the GDC in March 2011. After identifying dental technician registrants, a random sample was drawn, stratified by country. A power calculation indicated that a sample size of 363 would give a confidence interval of $\pm 5 \%$ around a proportion of 0.5 at $95 \%$ confidence level. In order to allow for a response rate of $60 \%$, a sample of 605 was drawn. Exclusion criteria were: non-UK address; having left the register in July 2011; now practicing in a different capacity; sharing a practice address with another selected DT. A preliminary letter included the address of an online survey provider (surveymonkey. com) where the survey questionnaire was accessible. The posting of a paper version of the questionnaire was followed by a second copy of the questionnaire and then a reminder/thank you postcard. As an incentive, respondents were entered into a draw for two £25 vouchers.

Job satisfaction was measured by the Warr-Cook-Wall scale. Reliability and validity data have been reported. ${ }^{9}$ The ten domains all appear to have good face validity with this sample. Each domain is rated on a seven-point scale from one (extreme dissatisfaction) to seven (extreme satisfaction). A Chronbach alpha coefficient of 0.93 was obtained for the ten domain scores, indicating good reliability in this group. Its use allows comparison with other recent surveys of UK DCPs. ${ }^{10-12}$
Questions on career intentions, including intention to quit their current post, were taken from the 2010 NHS Staff Survey in England undertaken by the Care Quality Commission, to permit comparisons with other professional groups working in primary care. ${ }^{13}$ In order to identify predictors of intention to leave dental technology respondents who indicated such an intention (ie responded 'agree' or 'strongly agree' to the statement 'I plan to leave dental technology for a different career') were compared to those who gave other responses across a range of possible predictors, before running a logistic regression analysis with intention to leave as the dependent variable. All analysis was conducted using SPSS v17.

\section{RESULTS}

Of the original sample of 605, 40 were found to be ineligible (left the register in July 2011, re-qualified in another dental care profession, shared a practice address with another selected DT). After second mailings and reminders had been sent, and individuals found to have changed address since initial selection followed up, a total of 193 complete or partly complete responses were returned, including 53 completed online. This represents a response rate of $34 \%$. The lower response rate than expected had the effect of increasing the margin of error from $\pm 5 \%$ to $\pm 7 \%$ at the $95 \%$ confidence level.

There was some indication that respondents may have had longer service than nonrespondents. The GDC register indicates date of registration, which was voluntary before 2008, rather than length of service. However, GDC registrant ID numbers are allocated sequentially, so those with higher ID numbers are more recent additions to the register. Using ID sequence as a proxy for length of service, a comparison of ID rank and response found a statistically significant difference, with non-respondents being indicated as having joined the register more recently $(\mathrm{t}=-=-2.313$, df 479 , $\mathrm{p}=0.021,95 \% \mathrm{CI}-0.124$ to -0.010 ). While female technicians had a higher response rate than males (42\% v $\underline{v s}$ 33) this difference was not significant $\left(\mathrm{X}^{2}=2.64, \mathrm{df}=1\right.$, $\mathrm{p}=0.104)$. Of the 193 respondents, $22 \%$ (40) were female (missing: nine), compared to $20 \%$ female of the complete GDC register of dental technicians.

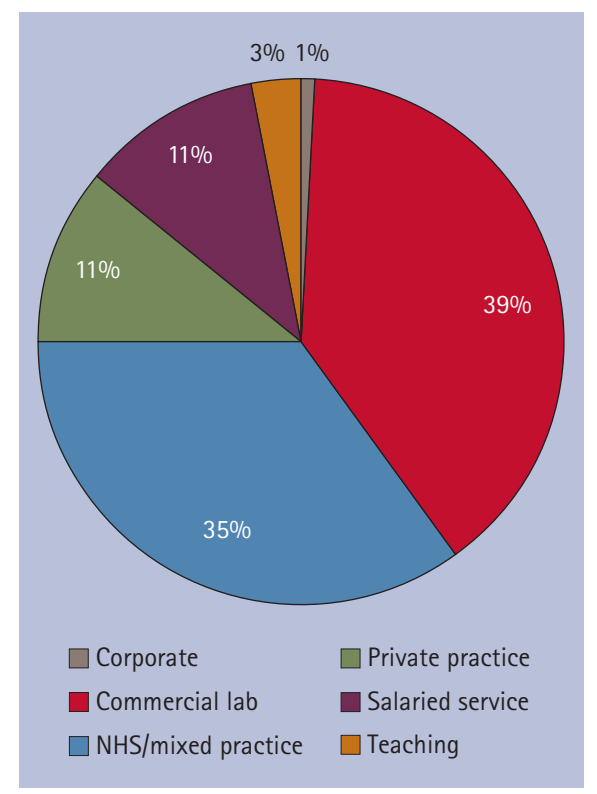

Fig. 1 Employment sector $(n=177)$

Female respondents tended to be younger than their male counterparts (mean age 38.2 years (SD 9.5) and 49.4 (SD 10.92) respectively: $t=5.77$, df $176, p=0.001)$. This age difference was reflected in length of service, which was almost twice as long for the male technicians (age 30.2 years (SD 12.39) and 16.6 years (SD 9.66) respectively: $t=5.98$, df $156, p=0.001)$. There was also a significant difference in the reported number of hours worked (44.5 hours (SD 10.7) for the men; 36.1 hours (SD 11.7) for the women: $t=3.66$, df $135, p=0.001)$. The majority of technicians were employees (70\%, 126); 24\% (46) were self-employed, one was mixed employed/self-employed, and 4\% (8) were not currently working (missing: 12). Just over one third worked in commercial laboratories or in NHS or mixed NHS/private general dental practices (Fig. 1).

Eighty-three percent (154) worked in England, 11\% (21) in Scotland, 3\% (6) in Wales, and 3\% (5) in Northern Ireland (missing: seven).

\section{Qualifications}

The largest group $(31 \%, 60)$ held a City and Guilds qualification in dental technology; 21\% (41) held a National Diploma; 13\% (26) held HNC or HND qualifications; $20 \%$ held additional specialist qualifications; 5\% (10) had a degree and 7\% (13) held other qualifications. Nine percent (17) were qualified through apprenticeships or 'grandfather' arrangements. 


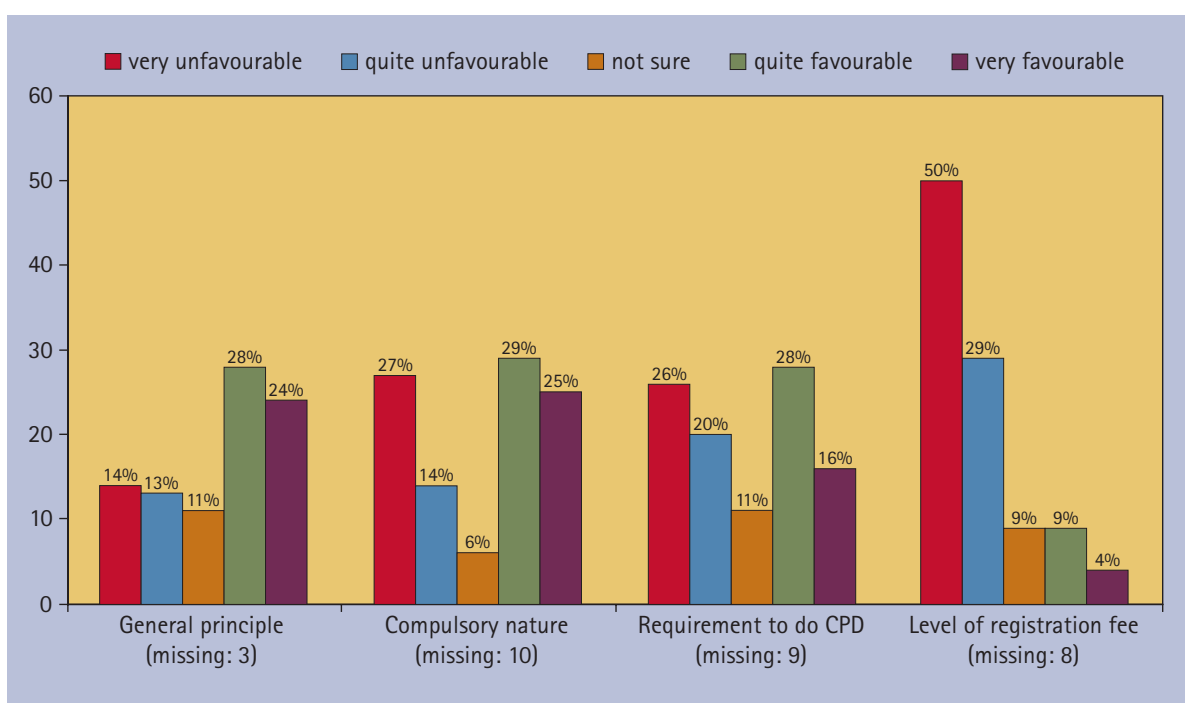

Fig. 2 Dental technicians' views on four aspects of GDP registration $(n=183-190)$

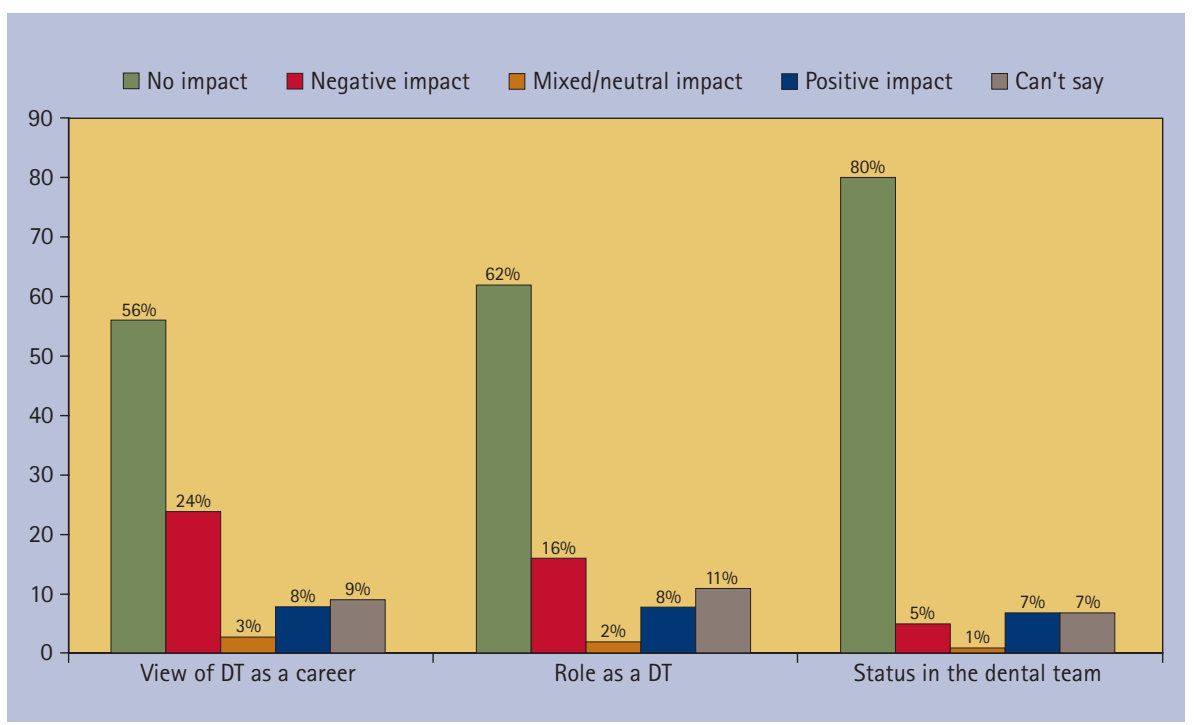

Fig. 3 Impact of GDC registration ( $n=189-191)$

\section{GDC registration}

Respondents were asked for their views on four aspects of GDP registration (Fig. 2).

Responses were generally favourable in regard to the general principle of registration, equivocal about registration and CPD being compulsory, and very unfavourable regarding the level of the registration fee. In reply to a subsequent question 64\% (121) of DTs said the fee was 'much too high' while 11\% (22) said it was 'about right'. Responses to the questions on requirement to complete CPD were related to the sector in which technicians worked. Those in NHS or mixed NHS-private practices tended to view mandatory CPD less favourably than those in the salaried service (ANOVA analysis of variance: $F=3.39$, df 5, 163, $\mathrm{p}=0.003$ ).

Respondents were asked what they felt the attitude of their employer was towards
GDC registration for DTs. Excluding those who said they were self-employed, 23\% (31) felt their employer was very or quite favourable, 31\% (41) said they were neutral, 35\% (47) said they were very or quite unfavourable, and 11\% (15) could not say (missing: one).

\section{Impact of GDC registration}

Technicians were asked if statutory registration had affected their view of dental technology as a career, their role as a DT or their status within the dental team (Fig. 3).

In terms of their career, negative comments (43) referred to 'financial costs or poor value for money' $(63 \%, 27)$, 'bureaucracy, red tape, or hassle' $(21 \%, 9)$, 'the profession being now less attractive' (19\%, 8), and that 'registration had increased unfair competition from unregistered or overseas laboratories' (7\%, 2). Positive comments
(16) referred to 'increased respect or professional status' (50\%, 8), 'higher standards of training or knowledge' $(31 \%, 5)$, 'a more attractive profession' $(13 \%, 2)$, 'a profession more secure against unregulated competition' $(6 \%, 1)$.

Of the 51 DTs who felt their role had been affected by registration, negative comments (30) referred to 'unnecessary bureaucracy, red tape or hassle' $(45 \%, 13)$; 'cost in time or money' $(37 \%, 11)$; 'lower morale or higher stress' $(13 \%, 4)$; 'lower professional status' $(3 \%, 1)$; and 'increased competition from unregistered or overseas laboratories' $(3 \%, 1)$. Positive effects (16) were: 'higher professional status' (50\%, 8); 'higher standards of training or knowledge' (44\%, 7); 'more security against unregulated competition' (5\%, 1).

Most (13) of the small minority of DTs who felt that registration had affected their status within the dental team said the impact had been positive, citing higher professional status $(46 \%, 6)$; higher standards of training or knowledge $(23 \%, 3)$; more security against unregulated competition $(15 \%, 2)$; higher morale $(8 \%, 1)$; and being able to charge more $(8 \%, 1)$. Negative comments (8) referred to lower status or increased dominance of the dentist (50\%, 4); lower morale or higher stress $(25 \%, 2)$; and cost or poor value for money $(25 \%, 2)$.

\section{CPD}

The mean number of reported CPD hours undertaken in 2010 was 29.1 (sd: 33.72 : missing 38). Asked what they felt about the amount of CPD they completed in 2010, 28\% (49) said it was 'too much', 50\% (88) said 'about right', 9\% (16) said 'too little', and 14\% (24) could not say (missing: 16).

Twenty-three percent (43) had their CPD paid wholly by their employer. Over half $(56 \%, 108)$ said they had to pay personally for all or some of their CPD, while others said they could only attend free courses, or had attended none due to cost. For those whose employers did not pay CPD costs, 54\% (68) said funding CPD was a problem for them. Funding problems were not significantly different across employment sectors $\left(X^{2}=2.72\right.$, df 5, $\left.p=0.744\right)$.

DTs were asked if the requirement to complete CPD had affected their role or the range of duties they undertook (Fig. 4).

The great majority of the 39 negative comments regarding the impact of 
mandatory CPD on their role as a DT referred to 'increased time pressure and costs' $(87 \%, 34)$. Other comments cited 'greater bureaucracy' $(10 \%, 4)$ and 'lower morale' $(3 \%, 1)$. Positive effects mentioned by five DTs were 'increased knowledge of patients' needs' (2), 'enhanced teamwork' (2), and 'increased knowledge in general' (1).

The 11 DTs who felt their duties had changed as a result of mandatory CPD were predominantly positive, referring to doing more implant work $(27 \%, 3)$, undertaking clinical dental technology training $(18 \%, 2)$; increased knowledge and confidence (18\% 2), more patient contact, specialist work relating to orthodontic surgery cases, managing others' CPD training, and CPR and health and safety duties (9\%, 1 of each). The one negative comment cited increased demands due to dual qualification as dental technician and dental nurse.

Technicians were asked three questions on training from the NHS 2010 Staff Survey. Table 1 compares their responses with those from qualified allied health professionals working in English PCTs.

DTs were more negative about the impact of training, learning and development than the comparison group of allied health professionals and these differences were highly statistically significant. DTs who reported completing more CPD hours were more likely to agree that post-qualification training helped them do their job better $(r=0.30, n=152, p=0.001)$; stay up to date with their job $(r=0.32, n=152$, $\mathrm{p}=0.001)$; and stay up to date with professional requirements $(r=0.26, n=152$, $\mathrm{p}=0.001$ )

DTs were asked what they felt the attitude of their employer was towards CPD. Excluding those who were self-employed, $20 \%$ (25) felt their employer was very or quite favourable, 27\% (36) said they were neutral, 43\% (57) said they were very or quite unfavourable and 10\% (13) could not say (missing: three).

\section{Job satisfaction and career intentions}

Mean score on the ten-point job satisfaction scale was 4.97 (SD 1.27, $\mathrm{n}=179$ ) on a scale of one (extreme dissatisfaction) to seven (extreme satisfaction). Taking the recognised cut-off of five on the scale as indicating satisfaction, 51\% were found to

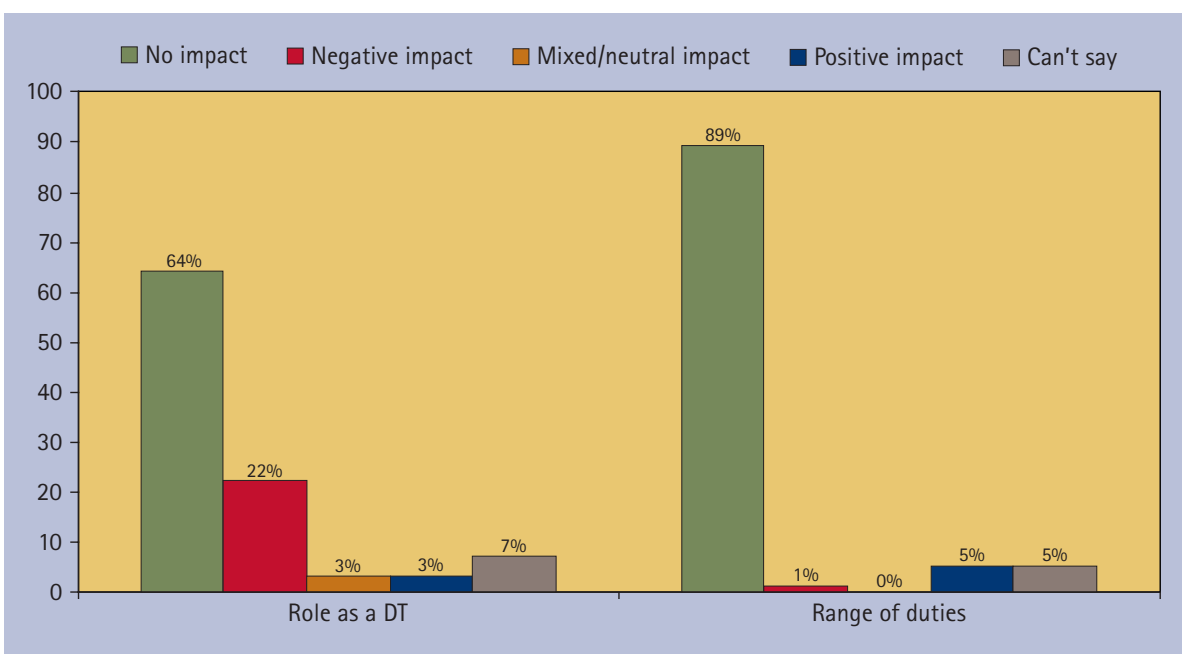

Fig. 4 Impact of mandatory CPD on DT role and range of duties $(n=181-182)$

Table 1 Views on the impact of post qualification training of dental technicians and other qualified allied health professionals ${ }^{13}$

\begin{tabular}{|c|c|c|c|c|c|c|}
\hline \multicolumn{2}{|c|}{$\begin{array}{l}\text { My training, learning and development } \\
\text { has helped me to: }\end{array}$} & \multirow{2}{*}{$\begin{array}{l}\begin{array}{l}\text { Strongly } \\
\text { disagree }\end{array} \\
18 \%\end{array}$} & \multirow{2}{*}{$\begin{array}{l}\text { Disagree } \\
21 \%\end{array}$} & \multirow{2}{*}{$\begin{array}{l}\begin{array}{l}\text { Neither } \\
\text { agree nor } \\
\text { disagree }\end{array} \\
27 \%\end{array}$} & \multirow{2}{*}{$\begin{array}{l}\text { Agree } \\
25 \%\end{array}$} & \multirow{2}{*}{$\begin{array}{l}\text { Strongly } \\
\text { agree } \\
8 \%\end{array}$} \\
\hline Do my job better & Dental technicians & & & & & \\
\hline & $\begin{array}{l}\text { Other qualified allied } \\
\text { health professionals }\end{array}$ & $3 \%$ & $5 \%$ & $21 \%$ & $56 \%$ & $14 \%$ \\
\hline \multirow{2}{*}{$\begin{array}{l}\text { Stay up to date } \\
\text { with my job }\end{array}$} & Dental technicians & $13 \%$ & $13 \%$ & $27 \%$ & $37 \%$ & $10 \%$ \\
\hline & $\begin{array}{l}\text { Other qualified allied } \\
\text { health professionals }\end{array}$ & $4 \%$ & $6 \%$ & $17 \%$ & $59 \%$ & $15 \%$ \\
\hline \multirow{2}{*}{$\begin{array}{l}\text { Stay up to date } \\
\text { with professional } \\
\text { requirements }\end{array}$} & Dental technicians & $11 \%$ & $9 \%$ & $27 \%$ & $39 \%$ & $14 \%$ \\
\hline & $\begin{array}{l}\text { Other qualified allied } \\
\text { health professionals }\end{array}$ & $4 \%$ & $5 \%$ & $14 \%$ & $60 \%$ & $17 \%$ \\
\hline
\end{tabular}

No. of technicians $=183$; no. of other qualified allied health professionals in PCTs $=3,463-3,476$. . 13 Proportions shown in bold indicate where agree/strongly agree combined proportion is significantly higher than in the other sample (difference in proportions test, confidence level $=99 \%)$

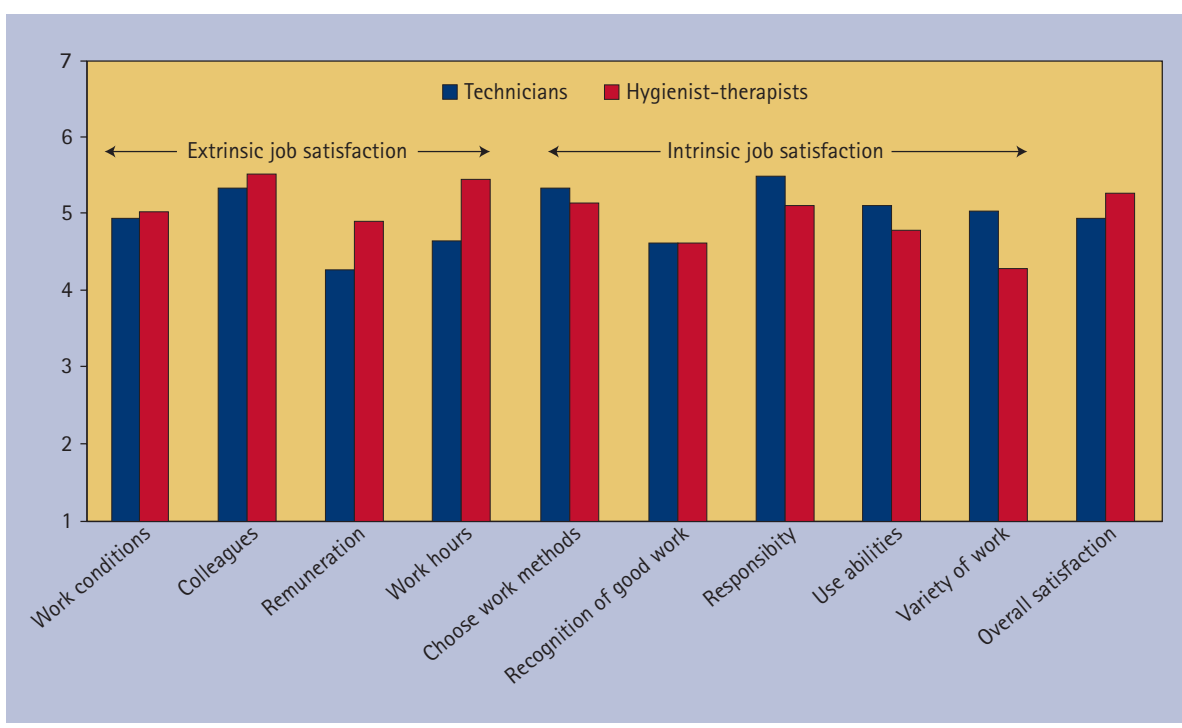

Fig. 5 Job satisfaction among dental technicians and dental hygienist-therapists. 1 = extreme dissatisfaction: 7 = extreme satisfaction. No. of technicians $=179$. No. of hygienist-therapists $=182$

be satisfied with their job. Figure 5 shows the variation across the ten satisfaction domains, and compares dental technicians with dental hygienist-therapists. ${ }^{14}$
As Figure 5 shows, job satisfaction relating to extrinsic aspects of the job tended to be lower than that relating to intrinsic aspects: mean extrinsic job satisfaction: 
Table 2 Career development of dental technicians and qualified allied health professionals ${ }^{13}$

\begin{tabular}{|c|c|c|c|c|c|c|}
\hline & & $\begin{array}{l}\text { Strongly } \\
\text { disagree }\end{array}$ & Disagree & Neither & Agree & $\begin{array}{l}\text { Strongly } \\
\text { agree }\end{array}$ \\
\hline \multirow{2}{*}{$\begin{array}{l}\text { There are oppor- } \\
\text { tunities for me to } \\
\text { progress in my job }\end{array}$} & Dental technicians & $12 \%$ & $23 \%$ & $27 \%$ & $26 \%$ & $11 \%$ \\
\hline & $\begin{array}{l}\text { Other qualified allied } \\
\text { health professionals }\end{array}$ & $14 \%$ & $33 \%$ & $25 \%$ & $26 \%$ & $2 \%$ \\
\hline \multirow{2}{*}{$\begin{array}{l}\text { I am supported to } \\
\text { keep up to date } \\
\text { with developments } \\
\text { in my field }\end{array}$} & Dental technicians & $7 \%$ & $17 \%$ & $30 \%$ & $34 \%$ & $12 \%$ \\
\hline & $\begin{array}{l}\text { Other qualified allied } \\
\text { health professionals }\end{array}$ & $5 \%$ & $14 \%$ & $20 \%$ & $55 \%$ & $6 \%$ \\
\hline \multirow{2}{*}{$\begin{array}{l}\text { I am encouraged } \\
\text { to develop my } \\
\text { own expertise }\end{array}$} & Dental technicians & $7 \%$ & $13 \%$ & $30 \%$ & $30 \%$ & $21 \%$ \\
\hline & $\begin{array}{l}\text { Other qualified allied } \\
\text { health professionals }\end{array}$ & $3 \%$ & $10 \%$ & $19 \%$ & $60 \%$ & $8 \%$ \\
\hline \multirow{2}{*}{$\begin{array}{l}\text { There is strong } \\
\text { support for training } \\
\text { in my area of work }\end{array}$} & Dental technicians & $16 \%$ & $20 \%$ & $32 \%$ & $18 \%$ & $15 \%$ \\
\hline & $\begin{array}{l}\text { Other qualified allied } \\
\text { health professionals }\end{array}$ & $8 \%$ & $23 \%$ & $29 \%$ & $35 \%$ & $5 \%$ \\
\hline \multirow{2}{*}{$\begin{array}{l}\text { I plan to get further } \\
\text { qualifications }\end{array}$} & Dental technicians & $19 \%$ & $26 \%$ & $33 \%$ & $13 \%$ & $9 \%$ \\
\hline & \multicolumn{6}{|c|}{ Other qualified allied health professionals: NA } \\
\hline
\end{tabular}

Table 3 Intention to quit among dental technicians and qualified allied health professionals ${ }^{13}$

\begin{tabular}{|c|c|c|c|c|c|c|}
\hline & & $\begin{array}{l}\text { Strongly } \\
\text { disagree }\end{array}$ & Disagree & Neither & Agree & $\begin{array}{l}\text { Strongly } \\
\text { agree }\end{array}$ \\
\hline \multirow{2}{*}{$\begin{array}{l}\text { I often think about } \\
\text { leaving this post }\end{array}$} & Dental technicians & $19 \%$ & $23 \%$ & $28 \%$ & $17 \%$ & $13 \%$ \\
\hline & $\begin{array}{l}\text { Other qualified allied } \\
\text { health professionals }\end{array}$ & $10 \%$ & $34 \%$ & $26 \%$ & $21 \%$ & $8 \%$ \\
\hline \multirow{2}{*}{$\begin{array}{l}\text { I will probably look } \\
\text { for a job at a new } \\
\text { organisation in the } \\
\text { next } 12 \text { months }\end{array}$} & Dental technicians & $36 \%$ & $24 \%$ & $23 \%$ & $12 \%$ & $6 \%$ \\
\hline & $\begin{array}{l}\text { Other qualified allied } \\
\text { health professionals }\end{array}$ & $13 \%$ & $38 \%$ & $25 \%$ & $17 \%$ & $7 \%$ \\
\hline \multirow{2}{*}{$\begin{array}{l}\text { As soon as I can find } \\
\text { another job, I will } \\
\text { leave this post }\end{array}$} & Dental technicians & $39 \%$ & $25 \%$ & $18 \%$ & $13 \%$ & $6 \%$ \\
\hline & $\begin{array}{l}\text { Other qualified allied } \\
\text { health professionals }\end{array}$ & $19 \%$ & $42 \%$ & $24 \%$ & $9 \%$ & $6 \%$ \\
\hline \multirow{2}{*}{$\begin{array}{l}\text { I plan to leave dental } \\
\text { technology for a } \\
\text { different career }\end{array}$} & Dental technicians & $33 \%$ & $22 \%$ & $25 \%$ & $15 \%$ & $5 \%$ \\
\hline & \multicolumn{6}{|c|}{ Other qualified allied health professionals: NA } \\
\hline
\end{tabular}

Table 4 Predictors of intention to leave dental technology profession

\begin{tabular}{|c|c|c|c|c|c|}
\hline \multirow[b]{2}{*}{ Funding CPD a problem } & \multirow{2}{*}{$\frac{t\left(X^{2}\right)}{(6.943)}$} & \multirow{2}{*}{$\frac{d f}{1}$} & \multirow{2}{*}{$\begin{array}{l}p \\
0.008\end{array}$} & \multicolumn{2}{|c|}{$\begin{array}{l}95 \% \mathrm{Cl} \text { of difference } \\
\text { lower upper }\end{array}$} \\
\hline & & & & & \\
\hline \multicolumn{6}{|l|}{ Job satisfaction re: } \\
\hline Remuneration & -3.311 & 172 & 0.001 & -1.845 & -0.467 \\
\hline Recognition for good work & -2.656 & 176 & 0.009 & -1.585 & -0.234 \\
\hline Amount of responsibility given & -2.515 & 39.868 & 0.016 & -1.644 & -0.179 \\
\hline Opportunity to use abilities & -2.268 & 174 & 0.025 & -1.273 & -0.088 \\
\hline Amount of variety in job & -2.019 & 173 & 0.045 & -1.279 & -0.014 \\
\hline Overall feeling about job & -3.520 & 176 & 0.001 & -1.656 & -0.466 \\
\hline \multicolumn{6}{|l|}{ Training \& development } \\
\hline There are opportunities to progress & -3.289 & 175 & 0.001 & -1.176 & -0.294 \\
\hline I am supported to keep up-to-date & -2.722 & 173 & 0.007 & -0.965 & -0.154 \\
\hline I am encouraged to develop expertise & -2.044 & 172 & 0.042 & -0.880 & -0.015 \\
\hline There is support for training in work & -3.101 & 172 & 0.002 & -1.198 & -0.266 \\
\hline Employed in a commercial lab & $(5.420)$ & 1 & 0.020 & & \\
\hline
\end{tabular}

4.80 (1.31); mean intrinsic job satisfaction 5.11 (1.33): $f=-5.05$, df $178, p=0.001$.

Career intentions were investigated through questions from the NHS 2010 Staff Survey, and compared with responses from qualified allied health professionals in English Primary Care Trusts. ${ }^{13}$ DTs were also asked whether they planned to seek further qualifications, and to leave the profession (Tables 2 and 3).

While DTs were more positive about opportunities to progress than were the comparison group, they were less likely to feel supported to train or encouraged to develop their expertise. There were no significant differences regarding intending to quit.

In order to identify predictors of intention to leave dental technology the 20\% (34) of technicians who gave a response of 'agree' or 'strongly agree' to the statement 'I plan to leave dental technology for a different career' were compared to those who gave other responses across a range of possible predictors (Table 4).

When the 12 variables in Table 4 were entered as independent variables in a logistic regression analysis with intention to quit dental technology as the dependent variable, only satisfaction with remuneration entered the model $(\mathrm{B}=-0.399$, df $1, p=0.001$ ).

\section{Open-ended comments}

A total of 88 open-ended comments were given by 71 technicians (37\% of the total) on the topics covered in the questionnaire. These comments were often extensive (totalling almost 3,500 words), and are reproduced in the online supplementary information.

All but 4 of the 88 comments were negative. One quote has been chosen at random to illustrate each of the themes that emerged.

- Criticism of the GDC's role, registration, regulations, bureaucracy (19 comments): 'on CPD in general I am in favour but I have not seen much benefit from the registration. Technicians in some quarters still have a hard time getting recognition for their work. We have some great dentists to work with who have embraced this, but there are still some who prefer technicians to be seen and not heard' 
- Inadequacy, poor provision, inaccessibility of CPD courses (16 comments): 'there are no courses near me and I have no time out of work to drive to the courses'

- The problem of unregulated workers and labs (11 comments): 'People still working who are not registered under a different title, don't pay fees etc, so registration is not favoured because of this'

- CPD costs, time needed, hours, hassle (10 comments): 'as work flow varies on a day-to-day basis we don't have the luxury to cancel appointments, therefore all CPD is done in our own time'

- Technicians' poor hours, pay, conditions, treatment (10 comments): 'it's the single hardest discipline in dentistry but the least well funded. Dentists are very poorly qualified in making prosthetics and have almost no understanding as to what is good quality prosthetics'

- The cost of registration/retention (9 comments): 'the dentists are the people that mispractice and cause problems with laboratories and patients as we read in the GDC magazine. As a dental technician to pay $£ 120$ a year for something that is forced on me and the threat of no work is outrageous'

- The cost of both registration and CPD (6 comments): 'the cost of GDC registration and $C P D$ courses are paid for by myself when I attend courses. I lose my wages so all together this is costing me a lot of money I can't afford. On top of this I haven't had a rise in my wages for the last three years. All technicians I know are struggling'

- The negative impact on patients (1 comment): 'compulsory registration and training has forced most lab work that NHS dentists used to do into the private sector for lab work crown and bridge and least maybe on nonprecious all metal crown. NHS patients requiring a preformed crown or bridge now have a choice - extraction and maybe denture or pay privately'

- Unspecific negative (2 comments): 'stable door horse has gone!'

- The positive value of training (4 comments): 'I am working for a keen employer who is teaching me a lot, I learn far more from a week at work than I would on a course. He goes on courses as they cost a lot, then he teaches me things that he has picked up.

\section{DISCUSSION}

The response rate of 34\% was lower than expected, and less than that obtained in the parallel survey of UK dental nurses (44\%). ${ }^{10}$ However, both these figures are higher than those achieved by the GDC-sponsored survey conducted by the Electoral Reform Services Research, where $25 \%$ of dental technicians and 25\% of dental nurses responded. ${ }^{1}$ Investigation of possible response rate bias suggests that respondents in the present study may under-represent more recently qualified technicians. The questionnaire failed to distinguish between verifiable and nonverifiable $\mathrm{CPD}$, which in hindsight may have been valuable to do.

The main finding of this study is that many dental technicians found little value in GDC registration and objected to the cost and time demands placed on them to complete what they saw as unnecessary CPD requirements. Fewer than one in four felt their employer supported them in completing CPD and many felt CPD had no or only a negative impact on their role (Fig. 3, Table 5). Those in NHS or mixed NHS-private practices viewed mandatory CPD less favourably than others. Technicians who felt they had done too much CPD in fact reported completing a similar amount in 2010 to those who felt the amount had been about right. In addition, negative views were more common among those who reported doing fewer CPD hours. These findings could be interpreted as indicating that the experience of CPD engenders more positive attitudes, or conversely that DTs who feel negatively towards CPD may be less likely to undertake it. Job satisfaction was relatively low, and dissatisfaction with earnings predicted intention to leave the profession. This may be linked with the relative isolation of dental technicians compared with other members of the dental team. A recent study of student DCPs concluded that the role of the dental technician was perceived as 'outside' the dental team due to lack of patient interaction, ${ }^{15}$ echoing the results of an earlier study which reported that many technicians feel undervalued as part of the dental team, leading to lower job satisfaction. ${ }^{16}$

The results of the present study are supported by the GDC's recent investigation of attitudes towards CPD. ${ }^{1}$ That survey found that only $15 \%$ of technicians agreed that they found it easy to take time off for CPD, 36\% felt motivated to do CPD and $47 \%$ said they would do CPD even if it was voluntary. These figures are the lowest among all the registrant groups in that survey. One third of technicians (32\%) saw no benefit in verifiable CPD, and 20\% thought there was no value in having core subjects within verifiable CPD, by far the highest proportion among the registrant groups. Technicians were also the most negative of all groups towards non-verifiable CPD. The report concluded that DTs were 'less likely to see value in CPD and more likely. to see it as something they have to do, rather than something they want to undertake.' ${ }^{1}$ Both the GDC report and the current study found that most DTs paid for CPD courses themselves and that cost was a major factor for technicians, with the results that no or low fees were often the main reason for selecting CPD courses.

Technicians in the present study were highly critical of the level of the annual registration retention fee, currently $£ 120$ pa, as were dental nurses responding to a parallel survey. ${ }^{10}$ Some technicians commented that their retention fees were subsidising Fitness to Practice proceedings that overwhelmingly involve dentists (see supplementary information, group (d)). Given that Fitness to Practice costs involving dentists are the single greatest outlay for the GDC, such criticism may be understandable. DCP's retention fees contribute over $£ 7$ million pa to the GDC's income. ${ }^{17}$

Judging from the results of this survey and the GDC's own report on CPD, ${ }^{1}$ it may not be an exaggeration to say dental technology is a profession in crisis. There is anecdotal evidence that a number of technicians refrain from calling themselves a 'dental technician' in favour of titles such as 'plaster technician' in order to avoid registration and CPD costs. While our survey suggests that technicians find their clinical activity rewarding, there is some way to go before the profession feels integrated into the dental team and convinced of the benefits of GDC registration and training 
through CPD. Dental technicians are vital to the success of today's highly sophisticated treatments offered by dentists. However, training programmes throughout the UK have dwindled in recent years. Unless the technical workforce is maintained or ideally increased significantly within the current regulatory framework, there is a risk that the demand for high quality laboratory work will not be able to be met in the UK, resulting in increasing reliance on unregulated foreign laboratories.

1. Electoral Reform Services Research. Registrant and provider perspectives on mandatory CPD in dentistry in the UK. JN B2204. London: General Dental Council, 2012. Online article available at http:// www.gdc-uk.org/aboutus/researchandconsultations/cpdreview/pages/cpd-research.aspx (accessed September 2012).

2. General Dental Council. Scope of practice. London: GDC, 2009. Online article available at http://www. gdc-uk.org/newsandpublications/Publications/ Publications/ScopeofpracticeApril2009[1].pdf (accessed September 2012)

3. General Dental Council. GDC annual report and accounts 2009. London: GDC, 2010. Online article available at http://www.gdc-uk.org/ Newsandpublications/Publications/Publications/ GDCannrep09web[1].pdf (accessed September 2012).

4. NHS Information Centre. NHS dental statistics for England:2010/11. (Table 5 London: The Health and Social Care Information Centre, 2011. Online article available at http://www.ic.nhs.uk/webfiles/ publications/007_Primary_Care/Dentistry/Dental_ Stats_Eng_2010_11/NHS_Dental_Statistics for_England_2010_11_Report_v2.pdf (accessed September 2012).

5. John J H. Thomas D, Richards D, Evans C. Regulating dental nursing in the UK. Br Dent J. 2002; 193: 207-209.

6. GDC requirements could harm nurse recruitment suggests former member. Br Dent J 2008; 204: 424

7. Ross M K, Ibbetson R J. Educational needs and employment status of Scottish dental technicians. Br Dent J 2005; 199(2): 97-101.

8. Eaton $K_{1}$ Brookes J, Patel R, Batchelor P, Merali $F_{1}$ Narain M. The impact of continuing professional development in dentistry: a literature review. London: GDC, 2011. Online article available at http://www.fgdp.org.uk/_assets/pdf/research/ final\%20impact $\% 20$ of\%20cpd\%20on $\% 20$ dentistry\%20november\%202011.pdf (accessed September 2012).

9. Warr P, Cook J, Wall T. Scales for the measurement of some work attitudes and aspects of psychological well-being. J Occ Psych 1979; 52: 129-148.

10. Turner S, Ross M K, lbbetson R J. The impact of
General Dental Council registration and continuing professional development on UK dental care professionals. (1) dental nurses. Br Dent J 2012; 213: E2.

11. Turner $S$, Ross M K Ibbetson R J. Job satisfaction among dually qualified dental hygienist-therapists in UK primary care: a structural model. Br Dent J 2011; 210: E5.

12. Turner $S$, Ross M K, lbbetson $R$ J. Dental hygienists and therapists: how much professional autonomy do they have? How much do they want? Results from a UK survey. Br Dent J 2011; 210: E16.

13. Care Quality Commission. 2010 NHS staff survey. London: Department of Health, 2011. Article available at http://nhsstaffsurveys.com/cms/index. php?page=historical-results (accessed September 2012).

14. Turner S, Ross M K, Ibbetson R J. Dually qualified dental hygienist-therapists: an underused resource? London: Presentation at British Association of Community Dentistry Conference, September 2009.

15. Morison S, Marley J, Machniewski S. Educating the dental team: exploring perceptions of roles and identities. Br Dent J 2011; 211: 477-483.

16. Bower E J, Newton P D, Gibbons D E, Newton J T. A national survey of dental technicians: career development, professional status and job satisfaction. $\mathrm{Br}$ Dent J 2004; 197: 144-148.

17. General Dental Council. Annual report and accounts 2010. London: GDC, 2011. Online article available at http://www.gdc-uk.org/newsandpublications/publications/publications/gdc_report_accounts_2010_ web.pdf (accessed September 2012). 